\title{
El segon exili del cardenal Vidal i Barraquer (1939-1943)
}

Manel Tarés Lagunas

maneltares@gmail.com

Universitat de Barcelona

Facultat d'Història

Departament d'Història i Arqueologia

Carrer de Montalegre, 6

08001 Barcelona

Resum. A partir d'unes memòries inèdites del canonge Joan Viladrich, secretari particular del cardenal Francesc Vidal i Barraquer, ens endinsem en el segon i definitiu exili del prelat tarragoní, el corresponent a la proscripció imposada per Franco. Presentem el cardenal com una figura incòmoda per al nou règim instaurat a Espanya, el qual aconseguí desprendre-se'n davant d'un Vaticà impassible o incapaç de trobar solució a l'afer. En els informes de Vidal al pontífex, es pot comprovar la seva desaprovació del règim franquista i la lluita infructuosa per mirar de revertir la seva situació personal.

Paraules Clau: cardenal Vidal i Barraquer, història de l'Església, exili, franquisme.

\section{The second exile of cardinal Vidal i Barraquer (1939-1943)} Авsтract. From the unpublished memoirs of the canon Joan Viladrich, the former private secretary of Cardinal Francesc Vidal i Barraquer, we analyse the second and final exile of the prelate of Tarragona, corresponding to his banishment imposed by Franco. We present the Cardinal as an uncomfortable figure for the new regime established in Spain, which managed to get rid of him in the face of an impassive Vatican and while unable to find a solution to the issue. In Vidal's reports to the Pope, one can see his disapproval of the Franco regime and the fruitless struggle to reverse the Cardinal's personal situation. 
KeYwords: Cardinal Vidal i Barraquer, history of the Church, exile, Francoism.

\section{La proscripció de Vidal i Barraquer}

El cardenal i arquebisbe de Tarragona Francesc d'Assís Vidal i Barraquer (I868-I943) fou un personatge essencial en la història de l'Església catòlica a l'Estat espanyol durant els anys de la dictadura de Primo de Rivera, la Segona República i la Guerra Civil. A l'igual que moltes figures que actuaren en la primera línia pública durant aquells períodes tumultuosos, la memòria del cardenal tarragoní ha estat utilitzada tant per mitificar-lo com per denigrar-lo. Ramon Muntanyola (I9I7-I973), el seu primer biògraf, el tragué del llarg oblit imposat pel franquisme, seguit pel treball d'altres historiadors procedents dels rengles eclesiàstics, que han efectuat un intensa activitat de recull documental i estudi de la història de l'Església, especialment, durant l'etapa republicana, amb una atenció particular sobre la figura del prelat. No exageraríem gens si afirmem que l'interès que despertà el cardenal en aquests estudiosos durant els anys setanta i vuitanta del segle passat comportà un acostament renovat a la història eclesiàstica d'aquells períodes, que permeté superar els rígids discursos historiogràfics establerts durant el franquisme, imbuïts d'una visió molt esbiaixada, parcial i victimista.

Les arrels de l'animadversió que generava el cardenal entre les files més properes a Franco, com també entre els sectors integristes de l'Església, s'han de cercar, almenys, en l'etapa de la dictadura de

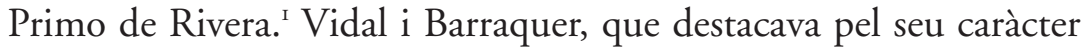

I Tanmateix, Ramon Corts ha demostrat recentment que encara cal anar una mica més enrere -almenys des què fou proposat promoure Vidal a la seu metropolitana de Tarragona- per començar a trobar les primeres reserves contra ell per una presumpta posició

Cercles. Revista d'Història Cultural, 24 (2021), 153-183.

ISSN: 1139-0158. e-ISSN: 1699-7468. DOI: 10.1344/cercles2021.24.1005. 
dialogant $\mathrm{i}$ conciliador, un aspecte remarcat per tots els seus biògrafs, era percebut pels elements espanyolistes coetanis com el cap espiritual de l'Església catalana i, per tant, el principal representant d'un determinat tarannà diferencial del clergat català, bo i convertint-se en el blanc dels militars primoriveristes i dels eclesiàstics més reaccionaris, que l'acusaren mantes vegades de separatista. Tanmateix, els seus biògrafs no han deixat d'assenyalar —en ocasions, amb recança- que el prelat no simpatitzava gaire amb el catalanisme polític. «Sembla com si tingués —als seus inicis— el sentiment que fer "catalanisme" era fer "política" i que això no era propi de "capellans"”, ha escrit Massot. ${ }^{2}$ En efecte, sempre repetia que l'Església no havia d'immiscir-se en política: «Tot per Déu, res per la política!», cridà el cardenal als capellans tancats a la presó de Montblanc durant la seva curta estada el juliol del 1936. No obstant això, sentia un gran compromís pastoral per la seva diòcesi i, per extensió, la província eclesiàstica catalana, per a la qual estava convençut que calien determinades solucions adaptades a les particularitats culturals i socials del país. En aquest sentit, doncs, la defensa de l'ús de la llengua pròpia en l'evangelització o la conveniència de comptar preferentment amb bisbes nascuts al territori, defensada sempre des d'una visió pastoral, foren dos dels assumptes que l'enfrontaren amb el directori militar. Aquest catalanisme pastoral ${ }^{3}$ feu que fos percebut, ja aleshores, com un símbol de resistència catalana contra el centralisme espanyolista

afecta al catalanisme. Aquestes estarien motivades perquè el germà del futur cardenal, Josep Vidal i Barraquer, s'havia presentat com a candidat regionalista a les eleccions legislatives del I916. Ramon CorTs, La Qüestió Catalana en l'Arxiu Secret Vaticà. De la Restauració a Primo de Rivera (I875-1923), Barcelona, Ateneu Universitari Sant Pacià, 20I7, p. 320.

2 Josep MAssot, "Vidal i Barraquer, metropolità de Catalunya», Quaderns de Pastoral, 53, maig de 1978, pp. 39-48.

3 Terme utilitzat per: Ramon CoRTs, «El cardenal Vidal i Barraquer i la dictadura de Primo de Rivera (1923-1930): pràctica i defensa d'un catalanisme», Revista de Catalunya, 249, 2015, pp. 48-59. 
de la dictadura. Tanmateix, Vidal defensava la integritat territorial d'Espanya amb el degut respecte per les especificitats regionals, alhora que lamentava els atacs contra els catalans.

Vidal i Barraquer sempre es mostrà obedient a les disposicions del seu superior jeràrquic, el Sant Pare. Aquest fou el seu principi d'actuació, que traspuava una adhesió incondicional al principi d'autoritat, bo i implicant la necessitat d'acatament a la jerarquia. ${ }^{4}$ En consequiència, per a ell, l'autoritat de l'Església estava per damunt de la del poder civil i per tant recomanava als sacerdots que no es manifestessin en qüestions polítiques. Aquest esperit motivà que Pius XI el triés, justament, per encapçalar les negociacions amb l'Estat sobre els punts de la Constitució republicana tocant als afers religiosos, tot i que acabaren fracassant pel brusc procés de laïcització que inicià el govern. ${ }^{5}$ Vidal, amb tota la càrrega conservadora pròpia d'un jerarca catòlic de l'època, ${ }^{6}$ sabé reconèixer el paper que havia de tenir l'Església en el nou règim polític que es pretenia construir. Tant el cardenal tarragoní, que, des de l'expulsió de l'arquebisbe de Toledo, el cardenal Segura, havia encapçalat la Conferència de Metropolitans, aleshores l'òrgan superior de l'Església espanyola, com el nunci Tedeschini, foren els càrrecs més destacats d'aquesta línia vaticanista i moderada. Així doncs, no escapa a ningú que aquells que han contraposat un Vidal i Barraquer possibilista i dialogant amb un Isidre Gomà, l'altre cardenal primat, intransigent i regalista, han presentat

4 Margarita Mauri, El pensament del Cardenal Vidal i Barraquer, Cambrils, Ajuntament, 2005, pp. 93-97.

5 Julio De la Cueva, «El laicismo republicano: tolerancia e intolerancia religiosa en la Segunda República española». Mélanges de la Casa de Velázquez, 44-I, 20I4, pp. 89-Io9.

6 Per a Batllori, Vidal i Barraquer era mentalment obert en el camp polític, però «no fou pas un home obert i precursor en el camp social, en part per la seva tendència a separar l'acció pastoral i cristiana de l'activitat social i política, però en part també pels condicionaments provinents del seu origen burgès i pel creixent caràcter antireligiós que anaven prenent els moviment socials, tant d'obrers com de camperols». Miquel BatLlori, L'Església i la II República espanyola, València, Tres i Quatre, 2002, p. 479.

Cercles. Revista d'Història Cultural, 24 (2021), 153-183.

ISSN: 1139-0158. e-ISSN: 1699-7468. DOI: 10.1344/cercles2021.24.1005. 
l'arquebisbe de Tarragona com una oportunitat perduda per a l'Església espanyola de la Segona República. ${ }^{7}$ Aquests dos corrents eclesiològiques eren perfectament percebudes pels contemporanis de l'època.

Amb el sollevament militar del juliol del 1936, una gran part de l'Església espanyola no tardà a adherir-s'hi, no només donant suport al bàndol antirepublicà, sinó també justificant i legitimant l'alzamiento nacional. Vidal i Barraquer es negà a signar la carta collectiva dels bisbes espanyols publicada el juliol del 1937, no tant perquè tingués opinions gaire diferents a les exposades en el text preparat per Gomà, sinó per qüestions tàctiques que obeïen al seu habitual tarannà prudent i pactista. El document denunciava la persecució religiosa a la zona republicana (ometent la repressió franquista) i justificava la missió dels militars rebels. Vidal estava convençut que la seva publicació podia agreujar la situació dels religiosos que romanien en zona republicana. El viatge del vicari general de Tarragona, Salvador Rial, a França i Itàlia, el setembre del 1938, per entrevistar-se amb Vidal i altres personalitats irrità els franquistes, que sospitaren que l'Església tarragonina estava colllaborant amb el govern republicà. Arran d'aquests fets, es congrià una agra aversió contra el cardenal tarragoní entre diversos elements del bàndol nacional. Es considerava que Vidal havia demostrat no estar gens identificat amb els ideals professats pel nou projecte polític dels vencedors. En efecte, el 2I de gener de 1939, el ministre d'Afers Exteriors, general Jordana, comunicava al nunci Cicognani que el cardenal era del tot incompatible amb el règim, cosa que justificava per a ells que no poguessin permetre la seva restitució ni admetre que el cardenal arquebisbe exercís cap mena de jurisdicció delegada sobre la seva seu. A continuació, a Roma, l'ambaixador espanyol a la Santa Seu, José

7 Enrique Berzal, «Las relaciones Iglesia-Estado durante la Segunda República Española: estado de la cuestión", Ivs Fvgit, 7, 1998, pp. 357-374.

Cercles. Revista d'História Cultural, 24 (2021), 153-183. ISSN: 1139-0158. e-ISSN: 1699-7468. DOI: 10.1344/cercles2021.24.1005. 
de Yanguas Messía, formulava al secretari d'Estat, Eugenio Pacelli, les tres ja conegudes acusacions contra el cardenal tarragoní: haver apostat per desenvolupar una Església regionalista catalana, haver-se negat a firmar la carta collectiva dels bisbes i haver tingut concomitàncies amb el Comitè roig de Barcelona i suposades relacions amb el govern basc. ${ }^{8}$ Ara bé, el Vaticà declarà que no hi havia cap fonament canònic per exigir la renúncia de la jurisdicció de l'arquebisbat. Al final, però, el cas del cardenal proscrit es convertí en un afer de fets consumats, ja que Franco no volgué avenir-se mai a cap mena de solució. Marquina opina que: «a pesar del prestigio del cardenal Vidal en la Secretaría de Estado, la suerte de este Cardenal estaba ya decidida antes de la muerte de Pío XI», cosa que indica que totes les gestions que realitzà posteriorment el Vaticà, com les de Vidal mateix davant la Santa Seu, foren inútils. ${ }^{9}$ El pas del temps i la mort del cardenal el setembre del 1943 posarien punt i final a la qüestió.

Després de la victòria franquista a la guerra, la capacitat de maniobra del cardenal restà anul.lada; no només per la seva absència física del país, sinó també per la impossibilitat d'actuar a través de vicaris generals nomenats i dirigits per ell. Vidal i Barraquer s'havia convertit definitivament en una figura incòmoda entre els sectors ultracatòlics i nacionalistes espanyols, motivada per la seva actuació ferma en defensa de l'Església catalana —entengui's com la de la província eclesiàstica tarraconense - i contrària a les intromissions governamentals en qüestions eclesiàstiques, així com per la postura conciliadora amb el poder civil adoptada durant la Segona República. En definitiva, els franquistes consideraven que el cardenal era del tot incompatible amb l'alineament ideològic que pretenien aconse-

8 Hilari Raguer, La pólvora y el incienso. La Iglesia y la Guerra Civil Española (I9361939), Barcelona, Península, 2001, p. 360.

9 Antonio Marquina, La diplomacia vaticana y la España de Franco (1936-1945), Madrid, CSIC, 1983, p. 133 . 
guir dins l'Església. No només temien el seu catalanisme, sinó que existia el convenciment que entre el clergat supervivent a Catalunya restaven reductes ben vius de sentiment catalanista, que tindrien en Vidal el far que podria revifar aquestes corrents, als quals es temia que s'hi afegissin diversos elements opositors. ${ }^{10} \mathrm{La}$ proscripció de $\mathrm{Vi}$ dal i Barraquer per Franco i el silenci imposat sobre la seva persona acabaren generant tota una llegenda al voltant seu, que interessà i illuminà una bona part de les posteriors generacions d'eclesiàstics catalans i mallorquins: Cardó, Albareda, Muntanyola, Batllori, Massot o Raguer.

\section{Les primeres vindicacions del cardenal Vidal i Barraquer: Viladrich i Cardó}

Vidal i Barraquer passà tot l'exili acompanyat sempre del seu secretari personal, el canonge solsoní Joan Viladrich i Viladomat (I897I993), a la cartoixa toscana de La Farneta. Només en sortien dues vegades l'any per fer breus estades a Roma, on el prelat tarragoní duia a terme algunes gestions davant la Santa Seu tocants el seu afer particular. I els estius, que els dos homes passaven a Suïssa, principalment a la cartoixa de La Valsainte. Des de l'estiu del 1939, hi coincidien amb la colla d'exiliats catalans reunits al voltant del mecenes Rafael Patxot. Fou precisament al país transalpí on la mort sorprengué el cardenal el I3 de setembre de 1943. La seva desaparició representà un cop fort per a Viladrich, que havia romàs al seu costat els set anys d'exili, inclosos en els vint-i-quatre anys de servei. Poc després de la mort del cardenal, Viladrich, que romangué a La Valsainte fins que, al cap de tres anys, pogué retornar a Tarragona reclamat pel nou

io Miguel Ángel Dionisio, El cardenal Isidro Gomá y la Iglesia española en los años treinta, Madrid, Universidad Autónoma de Madrid, 2010 [Tesi doctoral], p. 504. 
arquebisbe Arce Ochotorena, arreplegà la documentació d'exili per escriure una crònica del cardenal durant aquell període. ${ }^{I I}$ Un primer esborrany fou enllestit l'estiu del I945, com a molt tard, ja que el 2I d'agost Viladrich confiava la lectura del mecanoscrit, única còpia que tenia, al seu amic Anselm Maria Albareda (I892-I966), que exercia el càrrec de prefecte pontifici de la Biblioteca Apostòlica Vaticana, a Roma. Viladrich, que s'havia trobat sovint amb Albareda durant el conclave del març del I939, li confessava que:

Ningú no ho ha llegit. Us diré més. Ningú no sap que ni tan sols ho hagi escrit, com ningú no ha de saber que us ho he passat [...] Prego, doncs, d'ajudar-me a mantenir el secret per la vostra part, absolutament per a tothom. [...] La meva responsabilitat és molt gran, les coses a dir sovint molt delicades. Què es podrà dir? Què caldrà callar? [...] Necessito i us demano com un grandíssim favor el vostre illuminat consell, que us prego em doneu amb la màxima imparcialitat i sinceritat. [...] Ajudeu-me a vindicar la bona memòria del nostre plorat i tan terriblement humiliat i bescantat $\mathrm{Ca}[\mathrm{rdenal}] . .{ }^{\mathrm{I2}}$ Des del Cel Ell us ho pagarà... ${ }^{\mathrm{I}}$

Albareda acceptà l'encàrrec de llegir el voluminós treball i feu observacions generals sobre la idoneïtat de publicar-lo. Viladrich les resumia de la manera següent en una nota personal seva:

II Arxiu Municipal de Cambrils (AMCAM), Fons Arxiu Família Vidal-Barraquer, Memòries de mossèn Joan Viladrich.

I2 En la documentació consultada, ni Viladrich ni Albareda no utilitzen mai el nom del cardenal, sinó que s'hi refereixen, sobretot, amb adjectius o substantius escrits amb la inicial en majúscula: Difunt, Absent, Ell, Amic, Senyor. És un recurs que també s’observa en la correspondència entre Cardó i Sugranyes, en què el primer es refereix sempre a Vidal i Barraquer amb similars fórmules elusives. Vegeu: Jordi Giró, El catalanisme del Dr. Cardó, Valls, Cossetània, 2oor.

I3 AMCAM, Fons Arxiu Família Vidal-Barraquer, carta de Mn. Joan Viladrich al P. Anselm Albareda, 2I/8/1945. 
Creu ell que no hi ha cap perill d'emportar-me'l a Tarragona on el puc anar perfilant, però remarca bé que ho hauria de fer en fulls separats sens tocar una sola ratlla de ço que és el treball vist per ell. [...] Diu que caldrà fer-ne una edició anglesa, ultra la catalana i castellana. Encara diu que caldria fer un abreujat a l'abast de tothom. De moment, cal estar quiet; no hi [ha] possibilitat de pensar en publicacions com aquesta. Ja vindrà l'hora oportuna. ${ }^{\mathrm{I}}$

Viladrich reprengué les memòries la primavera del 1946 durant la curta estada a Suïssa en missió de treball, enviat pel nou arquebisbe. El is de maig tornava a Catalunya amb el mecanoscrit, que no s'ha conegut fins a la seva recent donació a l'Arxiu Municipal de Cambrils. ${ }^{I 5}$ Les memòries de Viladrich se centren, principalment, en l'etapa dels exilis, tot i que el primer capítol fa un repàs concís de l'actuació del prelat durant la primera dictadura i la Segona República, una "vindicació del Cardenal com apolític», tal com resa el títol.

La confecció d'aquestes memòries entre l'hivern de 1943-1944 i l'estiu de 1945 és, en part, complementària a la llarga elaboració del polèmic assaig escrit pel canonge Carles Cardó (I884-I958), també exiliat durant la guerra i la postguerra. Aquest coneixia segurament el projecte de Viladrich, ja que li feu costat després de la mort del cardenal, trobant-se tots dos homes a Suïssa. Lassaig de Cardó, que s'acabà publicant en francès a París el 1946, és una disquisició argumentada que s'atura a la Guerra Civil, ja que és un intent d'explicar-ne les causes, tot dedicant un capítol a les responsabilitats de l'Església en l'esclat del conflicte. En canvi, Viladrich se centra exclu-

I4 AMCAM, Fons Arxiu Família Vidal-Barraquer, Memòries de mossèn Joan Viladrich.

Is https://www.cambrils.cat/ca/l-ajuntament/comunicacio/la-familia-vidal-barraquer-cedeix-les-memories-inedites-de-joan-viladrich-a-12orgarxiu-municipal-de-cambrils. 
sivament en la figura de Vidal i Barraquer, especialment durant els anys d'exili. Aquesta és una crònica destinada a la defensa del cardenal de les acusacions del govern espanyol a partir de la reproducció íntegra de documentació personal coetània, bàsicament cartes i informes escrits per ser entregats al Vaticà. Entre un i altre document, Viladrich insereix breus valoracions personals sobre les circumstàncies viscudes, de les quals ell fou magnífic testimoni.

Cardó, que, d'acord amb Jordi Giró, «es considerà hereu i ambaixador ideològic del cardenal Vidal», ${ }^{16}$ explica el desenllaç de l'afer Vidal i Barraquer a partir d'una teoria original que pretén trobar les causes històriques que han desencadenat la Guerra Civil espanyola. El canonge vallenc distingeix dos corrents oposats en la història peninsular des d'una perspectiva de longue durée. ${ }^{\mathrm{I}}$ En paraules del seu amic Ramon Sugranyes, també exiliat: "La bona és la de la fe illustrada, servida per la caritat, i la dolenta la que pretén imposar la fe per la força, la de la croada de conquesta, la de l'espasa al servei de la Creu i de la Inquisició al servei de la política reial castellana». ${ }^{18} \mathrm{Per}$ a Cardó, doncs, la mala tradició hauria estat la desencadenant de la guerra (in)civil del I936, encarnada en les esquerres polítiques, la dreta catalana i l'extrema dreta política i religiosa castellana, així com la plutocràcia. ${ }^{\text {I9 }}$

I la mala tradició hauria dut, no sols la guerra, sinó també dues revolucions: l'anarquista de la rereguarda i el falangisme durant la guerra i, sobretot, la postguerra. Cardó aplica la tesi de l'antagonisme de les dues tradicions a l'Església espanyola del primer terç del segle, personificades en dues figures (Vidal i Barraquer i Gomà) i dos

I6 Giró, op. cit., 200I, p. 27.

I7 "[...] des del començament de la Reconquesta (7I8) fins a l'esclat de la guerra civil en I936». Carles Cardó, El gran refús, Barcelona, Claret, 1994, p. 79.

I8 Ramon Sugranyes, "El Dr. Carles Cardó en el seu exili: Les dues tradicions», Quaderns de Vilaniu, 28, 1995, pp. 87-96.

I9 Carles Cardó, Les dues tradicions, Barcelona, Claret, I977, p. I66.

Cercles. Revista d'Història Cultural, 24 (2021), 153-183.

ISSN: 1139-0158. e-ISSN: 1699-7468. DOI: 10.1344/cercles2021.24.1005. 
corrents o "partits eclesiàstics» (tarraconense contra toledanista), que representaven propostes ben diferents sobre la relació entre societat i religió. La valoració de Cardó respecte a la responsabilitat d'una part de l'Església espanyola en la gestació de l'alçament militar és fulminant: «Érem en temps de la República i molts dels individus que ocupaven els llocs jeràrquics de l'Església espanyola creien que la primera obligació de tot catòlic espanyol era la preparació de la guerra civil per a restaurar la monarquia protectora». ${ }^{20}$ En definitiva, Cardó demostra que el sollevament hauria estat il.legítim i contrari a les directrius pontifícies. No en va, una de les principals motivacions del seu assaig fou la defensa de la memòria del cardenal Vidal i Barraquer, tal com confessava l'autor a monsenyor Montini, substitut a la Secretaria d'Estat vaticana. ${ }^{21}$ Per a Cardó, amb la seva publicació s'acompliria una darrera voluntat del cardenal tarragoní, que, trobant-lo a Suïssa, li hauria demanat que escrivís una justificació teològica de la seva posició davant l'acte de proscripció que l'afectava. Vidal, de fet, pogué llegir l'últim esborrany abans de morir, però Cardó esperà expressament la fi de la guerra mundial per editar-lo, per si la victòria aliada feia caure la dictadura espanyola.

\section{Contra el cardenal de Tarragona}

Tant Cardó com Viladrich posen en evidència, en els seus escrits, les desavinences dels dos més alts jerarques eclesiàstics durant la Segona República, que anaven més enllà de l'àmbit estrictament ideològic per penetrar en el personal. ${ }^{22}$ Cardó és implacable amb Isidre Gomà (I869-1940), a qui situa en el bàndol dels desobedients amb les direc-

20 Cardó, op. cit., I994, p. 36.

2 I Ibídem, p. 78.

22 Corts, op. cit., 20I7, pp. 344-348.

Cercles. Revista d'História Cultural, 24 (2021), 153-183. ISSN: 1139-0158. e-ISSN: 1699-7468. DOI: 10.1344/cercles2021.24.1005. 
trius vaticanes d'acomodament amb el règim democràtic, els que haurien preparat «l'ambient de la guerra civil, de vegades quelcom més que l'ambient» i haurien fet créixer la llegenda negra contra el cardenal Vidal dins del món catòlic castellà, l'extrema dreta i el falangisme. ${ }^{23}$ També Viladrich es mostra crític amb Gomà, que, gaudint d'una gran influència en l'Església col-laboradora amb Franco, és acusat com un dels principals instigadors de les intrigues contra Vidal. A mitjan juny del 1939, aquest entregà un extens informe al Papa, que incloïa un apartat qualificat com a muy reservado, amb el títol «Relaciones Gomá-Vidal». ${ }^{24} \mathrm{Hi}$ acusava Gomà d'haver atiat la campanya contra la seva persona durant la guerra:

Consta por personas fidedignas que en la misma antecámara de Franco dijo [Gomà] que el Cardenal Vidal no haría más que perjudicar a la causa nacional, y en Roma añadió que se arrepentiría de no haber firmado la Carta Colectiva.

Davant d'aquest panorama, no és estrany que monsenyor Tardini, Secretari de la Congregació d'Assumptes Eclesiàstics Extraordinaris, després de la visita que li feu Vidal el 2I de febrer, qualifiqués la relació entre els dos prelats catalans com un «insanabile dissidio» i observés amb perplexitat: "Come farà la Spagna a risorgere spiritualmente quando i capi della Chiesa son così... scadenti? Dove si troverà la fonte della concordia?»». ${ }^{25}$

Tanmateix, durant el conclave del març del 1939, el cardenal de Toledo visità Vidal i Barraquer un parell d'ocasions i l'animà a no acceptar la dimissió de l'arquebisbat. De nou, Tardini, que fou infor-

23 Cardó, op. cit., I994, p. 60.

24 AMCAM, Memòries de mossèn Joan Viladrich, v. IV, pp. 5I-54.

25 Vicente CÁrcel, «Epistolario Vidal-Pacelli-Pizzardo-Montini y apuntes de la Secretaría de Estado (1936-1939)», Analecta Sacra Tarraconensia, 88, 2015, p. IOI3. 
mat d'aquestes trobades per Vidal mateix, percebé la desconfiança que li generava tot plegat a aquest últim: «l'E.mo Card. Vidal non ha troppa fiducia in queste assicurazioni e parole [les de Gomà]. Egli descrive l'E.mo Card. Gomá come un ambizioso». ${ }^{26}$ Encara en una lletra enviada al Papa el iq de juliol, Vidal reconeixia que: «Es de sobras conocida la actitud del Cardenal Gomá, que consiste en hacer ver que se mueve a favor del Cardenal Vidal, y en cambio se sabe lo que hace y dice a ciertas personas. ${ }^{27}$ Sens dubte, no podia considerar-se que la destral fos enterrada, però cal preguntar-se si Gomà era sincer o si era Vidal qui patia d'un excés de desconfiança.

En aquell informe, titulat Actitud injusta del Gobierno del General Franco contra el cardenal Vidal, que aquest entregà al pontífex, Vidal repassava els principals fets des del temps de la dictadura fins a la guerra. Hi considerava que la campanya contra la seva persona, com també contra el nunci Tedeschini i l'Acció Catòlica espanyola, dirigida per Herrera Oria, havia estat orquestrada durant la República de la mà d'elements integristes, membres de l'antiga dictadura $\mathrm{i}$ gent del partit Renovación Española. Vidal també denunciava que, durant la guerra, un grup de sacerdots refugiats a Roma, incitats pel marquès de Magaz, representant oficiós del govern de Franco prop el Vaticà, intensificaren la propaganda contra ell i Tedeschini, tergiversant «torcidamente la estancia en Lucca del Cardenal Vidal y su actuación silenciosa y caritativa en beneficio de los sacerdotes y fieles, cuyo alcance y finalidad desconocían». I acusava Gomà "y sus adláteres» (els bisbes Cartañà i Irurita, entre d'altres) d'haver intrigat contra la seva persona: "Llegó la campaña hasta el extremo de presentar al Cardenal como comunista y uno de los jefes de la Masonería española». ${ }^{28}$

26 Ibídem, p. IoI4.

27 AMCAM, Memòries..., p. 59.

28 Ibídem, pp. 43-57.

Cercles. Revista d'História Cultural, 24 (2021), 153-183. ISSN: 1139-0158. e-ISSN: 1699-7468. DOI: 10.1344/cercles2021.24.1005. 
El govern de Franco no formalitzà mai de manera escrita i clara les acusacions contra Vidal i Barraquer sobre les quals es basava la prohibició de reincorporació a la seu tarragonina. Els arguments es comunicaren sempre oralment en les audiències entre els diplomàtics espanyols i la Santa Seu o amb el mateix cardenal. L'ambaixador utilitzà sovint l'excusa d'un suposat ambient hostil contra Vidal que assegurava que existia a Tarragona (argument de l'odium plebis), el qual feia contraproduent el seu retorn. I encara volgué fer creure a la Santa Seu que, si el prelat posava els peus al país, no hi hauria garanties respecte a la seva seguretat personal. Aquests advertiments preocuparen Pius XII, segons explica el secretari del cardenal, que veia només en els falangistes la capacitat per atemptar contra el prelat. ${ }^{29}$

Mentrestant, el govern continuava ordenant investigacions i escorcolls a Tarragona per poder muntar càrrecs contra el cardenal absent. Aquest n’informava Pius XII en aquests termes: «Aún así no podrán en verdad aducir escrito, discurso o manifestación alguna con que justificar el pretendido catalanismo del Cardenal». ${ }^{30}$ Aquestes activitats inquisitives continuaren intermitentment al llarg de l'any següent. Al desembre del 1940, Vidal informava al Papa sobre un interrogatori que el fiscal de la ciutat havia practicat a Rial. Les preguntes feien referència a si el cardenal havia obtingut el permís del Vaticà per no signar la carta collectiva dels bisbes i si feu d'intermediari entre el govern republicà i el Vaticà. ${ }^{3 \mathrm{I}}$ Encara el juny del 194I, Vidal informava de les noves indagacions efectuades a Tarragona, aquesta vegada per aclarir la seva responsabilitat en els resultats de les eleccions del febrer del $1936 .{ }^{32}$

29 Ibídem, p. 137.

30 Ibídem, p. 59.

3I Ibídem, p. 68 undec.

32 Ibídem, pp. 72 ter.

Cercles. Revista d'Història Cultural, 24 (2021), 153-183.

ISSN: 1139-0158. e-ISSN: 1699-7468. DOI: 10.1344/cercles2021.24.1005. 


\section{La lluita infructuosa per tornar a Tarragona}

A mitjan juny del 1939, «quan ja Roma havia quedat neta de falangistes vinguts d'Espanya aquells dies», en paraules de Viladrich, referint-se a la visita que hi feu Serrano Suñer, el primer de juny, acompanyant els voluntaris italians repatriats de la guerra espanyola, Vidal demanava una nova audiència al Papa per conèixer de primera mà les gestions que s'haguessin dut a terme sobre el seu cas. S'hi expressava així d'emotiu:

He sufrido muchísimo y me doy cuenta de cuanto se ha tramado, al objeto de obligarme a dejar la Sede, por hombres de gobierno que estos días han querido aparecer ante el mundo entero como muy cristianos y obsequiosísimos con la Iglesia. No importa. Espero no me falte en lo sucesivo la gracia de Dios para sobrellevar con dignidad tamaña afrenta. ${ }^{33}$

El cardenal actuà amb summa diplomàcia per temptejar la seva situació amb el govern espanyol. En la seva primera entrevista amb el secretari d'Estat, el 8 de febrer, Vidal li consultà sobre la conveniència d'escriure al dictador, un gest que Pacelli considerà que seria inútil. En tot cas, Vidal ja havia preparat dos possibles textos per ser telegrafiats a Franco, els quals mostren l'extrema prudència emprada, uns telegrames que «retraten el Cardenal, sempre més inclinat a la conciliació que a l'estridència", segons valora Viladrich. ${ }^{34}$ Després de la mort de Pius XI, el dia abans en què estava previst l'acte de commemoració del desè aniversari dels pactes del Laterà on sembla que el pontífex havia de fer una al-lusió a la imminent reintegració del cardenal tarragoní, Vidal tingué la primera audiència amb Pius XII,

33 Ibídem, p. 43.

34 Ibídem, p. I6.

Cercles. Revista d'História Cultural, 24 (2021), 153-183. ISSN: 1139-0158. e-ISSN: 1699-7468. DOI: 10.1344/cercles2021.24.1005. 
el 7 de març, en què li demanà autorització per presentar-se a Tarragona. Però, per al Papa, encara no era arribat el moment. Al novembre, retornat de les vacances a Suïssa, tingué una altra audiència amb el pontífex. Viladrich comenta que, si bé el cardenal pogué confirmar novament que la Santa Seu no el forçava a la dimissió, també observà que mancava decisió i fermesa per imposar una solució al govern espanyol, malgrat les insistències de Vidal. En aquella ocasió, el nou secretari d'Estat, el cardenal Maglione, li etzibà:

"Què vol, Sr. Cardenal, que trenquem pel cas de Tarragona les relacions diplomàtiques amb Franco?».35 Era el nou tarannà del Vaticà: política possibilista amb Franco i ambigüitat davant el feixisme. Cal tenir present que poc després de la seva entronització, Pius XII felicitava públicament el dictador espanyol per la seva victòria amb un elogi desmesurat mitjançant un missatge radiofònic.

En aquella primeríssima postguerra, tal com estava l'ambient a Tarragona, després de la detenció de Rial i l'estranyament del substitut Vives, així com l'ocupació permanent del Palau Arquebisbal per funcionaris del Cos de Museus - que no abandonaren l'edifici fins a l'últim dia del 1940—, ningú no gosava aixecar la veu en públic a favor del legítim arquebisbe. El bisbe d'Urgell reconeixia aquestes circumstàncies: «No pueden, sin embargo, manifestarlo en público por temor al Gobierno y a algunos falangistas». ${ }^{36}$ D'altra banda, el vicari Rial, reintegrat sense problemes a l'arquebisbat, no s'estava de demanar el retorn del cardenal en les seves comunicacions amb la jerarquia vaticana. Vidal se'n feia ressò dient a Pius XII: «el Clero diocesano de Tarragona espera con grandes ansias el retorno de su querido Cardenal, que las cosas irían mejor si estuviese allí y que hay

35 Ibídem, p. 66.

36 Ibídem, p. 58.

Cercles. Revista d'Història Cultural, 24 (2021), 153-183.

ISSN: 1139-0158. e-ISSN: 1699-7468. DOI: 10.1344/cercles2021.24.1005. 
algunos asuntos que solo su presencia puede solucionar bien». ${ }^{37} \mathrm{De}$ fet, aprofitava quasi totes les audiències amb el Papa —almenys dues l'any- per exposar l'increment de veus que, des de Tarragona, en reclamaven el retorn. D'aquesta manera, contrarestava l'argument de l'odium plebis sovint esgrimit a Roma per l'ambaixador Yanguas Messía.

Tanmateix, a partir d'aquell moment, l'hivern del 1940 que passà novament a la cartoixa toscana, Vidal i Barraquer no només assumí els fets, sinó que s'imposà a si mateix un silenci discret per no pertorbar la imatge de la Santa Seu. Li dolia que el seu cas no s'hagués explicat bé públicament i lamentava les informacions esbiaixades i errònies que publicava, a vegades, la premsa. Cardó, en una carta al seu amic Sugranyes del 9 d'octubre, es referia al cardenal de la manera següent:

Ha passat tres mesos entre nosaltres el nostre patriarca i primat. Està més ferm que mai, amb una visió de les coses que em sorprèn per la seva justesa. Ja deveu saber que li han barrat el camí del retorn. Està molt descoratjat i fins he notat que, en un any que no l'havia vist, ha perdut bastant de la seva agilitat mental. No és estrany. Té 72 anys i sofreix molt moralment. ${ }^{38}$

En els seus escrits al Papa, a Vidal no se li escapava la seva indignació per la immobilitat vaticana, o més ben dit, que no fos possible parar els peus a un govern autoproclamat catòlic que, per contra, violava les bases del dret canònic i s'entremetia en excés en afers interns de l'Església. Vidal apujà el to en els seus informes, fins al punt d'amenaçar de fer declaracions a la premsa sobre el seu cas o, fins i tot, publicant una pastoral. Amb aquest canvi d'actitud, pressionava

37 Ídem.

38 GIRó, op. cit., 20OI.

Cercles. Revista d'História Cultural, 24 (2021), 153-183. ISSN: 1139-0158. e-ISSN: 1699-7468. DOI: 10.1344/cercles2021.24.1005. 
perquè el Vaticà adoptés una postura ferma i resolta respecte al seu cas. Suggerí, per exemple, que, mentre Franco no cedís, no es concedís cap capell cardenalici a un prelat espanyol i no es tinguessin en compte les propostes del govern per cobrir seus vacants. Era el temps en què l'Estat negociava un nou Concordat amb l'Església romana, que no arribà fins molts anys després, el I953. Mentrestant, s'assolí un acord bilateral sobre el nomenament de bisbes. Amb la firma d'aquest conveni el juny del I94I, Vidal veia arguments suficients per a la seva reincorporació a la seu tarragonina. El 6 de juny, doncs, escrivia a Pius XII per insistir-li que era arribat el moment de la reintegració:

[...] puesto que si ya es hora de que se haya puesto fin a una interinidad que afecta a un tercio de las sedes españolas, no hay porque se haga una excepción con la de Tarragona. [...] Ningún momento más oportuno que el presente para que el Vaticano exija y urja del Gobierno el retorno puro y simple de[l] Cardenal a su Sede. ${ }^{39}$

Per a Viladrich, aquest nou informe al Papa havia estat "de tons una mica forts, però ben objectiu i fonamentat». ${ }^{40} \mathrm{Al}$ mateix temps, el cardenal començava a posar en dubte l'actitud del nunci Gaetano Cicognani, perquè «no ha sido muy visible su intervención para amparar al Cardenal contra los tuertos de que ha sido y sigue siendo todavía víctima por parte de un Gobierno católico». ${ }^{4 \mathrm{I}}$ Més endavant, el 28 de juny de 1942, insinuava al pontífex que fos designada una altra persona diferent del nunci per negociar el seu afer, fortiter et suaviter, directament amb Franco. ${ }^{42}$

39 AMCAM, Memòries..., pp. 72ter-72quinq.

40 Ibídem, p. 75.

4I Ibídem, p. 68 nov.

42 Ibídem, p. 99-4.

Cercles. Revista d'Història Cultural, 24 (2021), 153-183.

ISSN: 1139-0158. e-ISSN: 1699-7468. DOI: 10.1344/cercles2021.24.1005. 
El conveni bilateral del juny del I94I era, doncs, una bona oportunitat — tot i que acabà frustrada — per forçar el retorn de l'arquebisbe de Tarragona, una ocasió que generà moltes expectatives a la ciutat. Ja l'any anterior, l'empresari tarragoní Xavier de Muller i de Ferrer, membre d'una família ben relacionada amb els Vidal i Barraquer, havia adreçat una súplica al Sant Pare demanant el retorn de Vidal. ${ }^{43}$ Probablement, el mateix Muller fou el principal instigador d'una segona acció collectiva des de Tarragona quan, vencent amb coratge l'ambient inquisitiu del règim i sense que el cardenal Vidal en fos prèviament informat, hom decidí enviar dues cartes a Pius XII, l'una per part del clergat, encapçalada per la firma de Salvador Rial, la màxima autoritat eclesiàstica de la diòcesi de Tarragona en absència de l'arquebisbe proscrit, i l'altra d'una alta representació de la feligresia local. Les dues missives foren entregades al papa per l'abat Aureli Escarré el I4 de novembre de 194I, juntament amb una nota en què s'assenyalava directament el general Franco com a principal oponent al retorn del prelat, atès que «ninguno de los Ministros del actual Gobierno es contrario al Sr. Cardenal». Per contra, els principals oponents a la reintegració de Vidal i Barraquer serien, d'acord amb aquesta nota: «[...] los elementos monárquicos que apoyaron al General Primo de Rivera; Acción Española, uno de cuyos elementos destacados es el actual Embajador cerca de la Santa Sede [Yanguas Messía]»; tanmateix, «son numéricamente pocos, y su prestigio político ha sufrido fuerte mengua». ${ }^{44} \mathrm{La}$ carta també incloïa diverses declaracions favorables al retorn de Vidal i Barraquer realitzades per algunes autoritats locals en converses privades, amb les quals es pretenia demostrar l'ambient favorable al seu retorn, bo i negant l'existència d'un odium plebis a la ciutat. Per exemple, l'influent Cap Provincial de la Falange, el reusenc José María Fontana, «uno de los que

43 Ibídem, p. 80.

44 Ibídem, p. 76.

Cercles. Revista d'História Cultural, 24 (2021), 153-183. ISSN: 1139-0158. e-ISSN: 1699-7468. DOI: 10.1344/cercles2021.24.1005. 
más ambiente hicieron contra el Sr. Cardenal, a pesar de que no le ha tratado y apenas le conoce», hauria mostrat un canvi d'opinió significatiu envers la qüestió del retorn, "diciendo ahora que se ha exagerado la nota de hostilidad a Su Eminencia, que no hay motivo justo para tratarle como se le trata, y otras frases análogas, que manifiestan claramente una especie de arrepentimiento». ${ }^{45}$

En paral.lel a aquests missatges dirigits a Pius XII des de Tarragona, els bisbes de Catalunya, com a sufraganis de la província eclesiàstica catalana, adreçaren una carta col-lectiva al general Franco en què, després de mostrar plena adhesió al projecte nacional, l'hi exposaven la manca de lideratge espiritual en què es trobava Catalunya i pregaven la reintegració del cardenal Vidal i Barraquer. La iniciativa del document fou del bisbe de Solsona, Valentí Comellas, alhora el més antic de l'episcopat català. La carta fou entregada a Fèlix Millet, president de la Federació de Joves Cristians de Catalunya, alhora empresari financer ben relacionat amb el règim, perquè la fes arribar a Franco. En les seves memòries, Viladrich explica les peripècies per fer arribar el document al seu destinatari final, d'acord amb el que els contà Millet mateix en una trobada posterior a Roma. Sembla que l'empresari català hauria estacionat momentàniament el cotxe en un carrer de Madrid i, en tornar, el document hauria desaparegut. Aleshores, hagueren de redactar-ne un de nou, però aquesta vegada signat només pel bisbe Comellas en nom de tots els bisbes coprovincials, a fi d'estalviar el procés de tornar a passar-lo a firmes i evitar possibles retractaments d'alguns dels signants previs si coneixien l'incident de la sostracció de la carta.

Franco no donà cap resposta a la carta dels bisbes catalans. Tampoc no en digué res durant la pomposa visita de propaganda a Cata-

45 Ibídem, p. 82. Sembla que Fontana hauria dit a un sacerdot: «Jo m’havia cregut que el cardenal Vidal i Barraquer era una bandera política; ara veig que va actuar com un bisbe.» Ramon Muntanyola, Vidal i Barraquer, cardenal de la pau, Barcelona, Abadia de Montserrat, 2017, v. I, p. I9.

Cercles. Revista d'Història Cultural, 24 (2021), 153-183.

ISSN: 1139-0158. e-ISSN: 1699-7468. DOI: 10.1344/cercles2021.24.1005. 
lunya a la fi del gener del I942, és a dir, ni durant la trobada que tingué amb els bisbes a Montserrat el dia 25 ni a la visita a Tarragona el dia 30, on entrà sota pal.li a la catedral sense fer cap referència explícita a l'arquebisbe proscrit. Viladrich és, a la força, molt crític amb l'actitud dels tarragonins en aquella ocasió:

[...] deixant perdre una ocasió que era magnífica (i creiem, en la nostra modèstia, obligada) de manifestar d'alguna manera llavors mateix o en document posterior el dol de l'Arquebisbat per l'exili ja massa llarg i immotivat del Pastor. Franco devia dir que s'havia passejat per dintre la mateixa casa del Cardenal i no havia vist sinó obsequis, reverències i alegria; cap mostra ni expressió de plany, ni cap petició, ni la més mínima alllusió al Pastor absent. [...] Potser hi va mancar un quídam disposat a anar a la presó, si calia. ${ }^{46}$

En públic, els tarragonins hagueren de callar i fer el paperot davant Franco, però, després de la seva marxa, hi restà molta acritud. Rial, per exemple, escrigué a Pla i Deniel, acabat de nomenar arquebisbe de Toledo, sobre aquella visita del dictador:

No son para escribir aquí los duros comentarios que se hicieron contra el Caudillo Franco al verle el 30 pdo., colocado en el Trono del Sr. Cardenal en nuestra catedral a la hora del Te Deum. Aquí nadie cree que sean católicos de verdad unos gobernantes que se arrogan la facultad de juzgar a un Cardenal y no le dejan posesionarse de su Sede, a pesar de las sanciones canónicas con que la Iglesia garantiza el ejercicio de la Autoridad Eclesiástica. ${ }^{47}$

46 AMCAM, Memòries..., p. 95.

47 Raguer, op. cit., 200I, p. 386.

Cercles. Revista d'Historia Cultural, 24 (2021), 153-183. ISSN: 1139-0158. e-ISSN: 1699-7468. DOI: 10.1344/cercles2021.24.1005. 
$\mathrm{Al}$ parer de Rial, aquella situació humiliant va fer que molta gent fos conscient, aleshores, de la injustícia que s'estava cometent contra l'arquebisbe legítim de Tarragona. Així li ho manifestava novament a Pla i Deniel: «[...] cuanto más aumenta el prestigio del Sr. Cardenal, tanto más disminuye la reputación de los que le retienen desterrado».

Per les informacions que rebia dels seus corresponsals des de l'interior d'Espanya, Vidal i Barraquer es feia la idea que l'impediment al seu retorn a Tarragona era, cada vegada més, fruit de l'actitud personal de Franco. Ni tan sols la crisi política del 1942, quan Serrano Suñer sortí del govern, no es produí cap canvi en la postura envers el cardenal tarragoní. En aquesta nova conjuntura, en un moment que alguns autors han definit com de millora significativa en les relacions entre el Vaticà i Espanya,$^{48}$ Pius XII feu l'últim intent per intercedir en persona a favor del cardenal Vidal: escriure directament al general Franco. El resultat, però, fou fruit de la timidesa del plantejament del primer i la resposta tallant del segon. En efecte, Franco tancà l'intercanvi epistolar el 24 de febrer de 1943, negant-se taxativament a un acord sobre l'afer i al.legant la total incompatibilitat del cardenal amb el règim:

[...] en el cardenal Vidal y Barraquer se polarizan todavía las pasiones de grandes sectores españoles y que su vuelta traería trastornos a la paz política y la paz religiosa. [...] Este juicio público, desgraciadamente muy extendido, surgió ya bajo la Monarquía, se agravó bajo el imperio de la República y tuvo su más alta expresión con motivo de nuestra Cruzada. ${ }^{49}$

Aquesta resposta de Franco hauria molestat alguns membres de la cúria vaticana; així es desprenia de la carta que el nou ambaixador

48 Pablo Martín de Santa Olalla, De la victoria al Concordato. Las relaciones IglesiaEstado durante el "primer franquismo» (I939-1953), Barcelona, Laertes, 2003, p. 78.

49 Marquina, op. cit., I983, p. 656.

Cercles. Revista d'Història Cultural, 24 (2021), 153-183.

ISSN: 1139-0158. e-ISSN: 1699-7468. DOI: 10.1344/cercles2021.24.1005. 
al Vaticà, Domingo de las Bárcenas, escrigué al ministre Jordana, en què li deia que elements del "partido francés, nuestro tradicional enemigo en el Vaticano [...] ejercían de nuevo presión para desvirtuar el saludable efecto de la contestación del Caudillo al Papa». ${ }^{50}$ De totes maneres, amb aquest nou i definitiu revés, Vidal i Barraquer perdia tota esperança de retorn, bo i esllanguint-se en el seu refugi italià. L'ambaixador, que el visità al final de maig del 1943, escrigué d'ell que les seves «dotes de inteligencia y corazón quizás se evalúen excesivamente». ${ }^{\mathrm{SI}} \mathrm{El}$ devia trobar fastiguejat, poc inclinat a rebre aquell nou buròcrata $\mathrm{i}$ haver-se d'humiliar davant del flamant representant d'un règim que no havia tingut cap mena de mirament per un prelat de l'Església. Si bé l'opinió expressada per l'ambaixador és grollera i desconsiderada - tot $i$ haver estat expressada en privat-, pot relacionar-se amb una altra breu valoració més fefaent sobre l'estat anímic del cardenal tarragoní, aquesta vegada expressada pel canonge Cardó en una correspondència privada l'octubre del 1940: «en un any que no l'havia vist, ha perdut bastant de la seva agilitat mental».52 Sens dubte, el cardenal havia sofert molt en silenci.

\section{Vidal i Barraquer davant del franquisme}

Arran de la proscripció confirmada pel govern espanyol, Vidal i Barraquer experimentà un ràpid desencantament amb el bàndol que, fins aquell moment, havia preferit que fos el vencedor de la guerra. A la primeria, el cardenal tenia esperances en la clemència promesa per Franco, però acabà comprenent que el nou règim pretenia polititzar la vida religiosa del país. Més enllà del seu cas particular, Vidal

so Ibídem, p. 666.

5I Ídem.

52 GIRó, op. cit., 200I.

Cercles. Revista d'História Cultural, 24 (2021), 153-183. ISSN: 1139-0158. e-ISSN: 1699-7468. DOI: 10.1344/cercles2021.24.1005. 
lamentava la complicitat entre l'Església espanyola i el nou règim instaurat. En referència a l'actitud de la primera durant el període republicà, feia la següent consideració al papa:

La actuación de los Obispos y Clero en general ha sido demasiado política en perjuicio de la autoridad e independencia que debe siempre mantener la Jerarquía. [...] El tan proclamado derecho a la rebeldía ha troceado en muchos eclesiásticos el espíritu de caridad, suavidad y mansedumbre evangélicas por el de violencia, represalias, castigo.53

El cardenal hi denunciava, doncs, la politització de l'Església i els estralls que havia provocat la teoria del dret a la rebel.lió (exposada, per exemple, el 1934 pel canonge Aniceto Castro). ${ }^{54}$ Precisament, l'assaig de Cardó demostrava les conseqüències devastadores que havien tingut aquestes tesis ultramuntanes. Novament, en una audiència amb Pius XII, el I9 de desembre de I940, Vidal es referia a l'actitud dels religiosos en l'Espanya franquista, especialment al posicionament acrític dels bisbes, que s'avenien alegrement al nou règim instaurat:

[...] da pena ver como los obispos se prestan a hacer una religión patriotera a base de Misas de campaña, Te Deums, etc. Las tan de moda peregrinaciones al Pilar más que formar al pueblo en la verdadera piedad tienden a hacer ambiente de hispanidad. ${ }^{5}$

I, en concret, carregava contra Gomà, que s'equivocà «al apoyar tan decidida y abiertamente al General Franco, mezclando la política con la religión». ${ }^{56}$ Ja ho havia advertit anteriorment al Sant Pare el

53 AMCAM, Memòries..., p. 54.

54 Raguer, op. cit., p. 33.

55 AMCAM, Memòries..., p. 68 quindec.

56 Ibídem, p. 68-22.

Cercles. Revista d'Història Cultural, 24 (2021), 153-183.

ISSN: 1139-0158. e-ISSN: 1699-7468. DOI: 10.1344/cercles2021.24.1005. 
juny del 1939, quan jutjava l'actuació dels bisbes massa allunyada d'una desitjable neutralitat política, cosa que havia de portar conseqüències negatives per a la religió:

Ello dificulta el acercamiento a la Iglesia de las personas indiferentes y apartadas de la Religión porque a través de los Obispos y del Clero la juzgan identificada con el partido dominante, por el cual muchos no sentirán simpatías, y con la clase rica. ${ }^{57}$

Aquest és un argument recurrent en el pensament de Vidal, que sempre apostà per la prudència com la millor manera de guanyar-se els esperits dels poc creients. D'aquesta manera, algunes posicions del prelat tarragoní — com la negativa de firmar la carta collectiva dels bisbes, el rebuig a l'integrisme religiós o la denúncia del posicionament excessivament polític del clergat de la postguerra-s'han d'interpretar, també, com una tàctica per aconseguir un fi més elevat: la recatolització del país, sempre des de la persuasió i la suavitat. Allò que denunciava Vidal era el nacionalcatolicisme: la simbiosi entre el catolicisme espanyol i la concepció nacionalista i tradicionalista de les noves autoritats; un nacionalisme reaccionari i excloent en què la religió catòlica era un ingredient bàsic de la identitat collectiva del qual s'havia de fer gala i ostentació. ${ }^{58}$ Durant aquells primers anys del règim en què el predomini del falangisme era gran, Vidal evidencià sovint el perill que implicava això per als interessos catòlics, tal com anotava, per exemple, en uns apunts personals tan aviat com el 9 de febrer de 1939: «en regímenes totalitarios que controlan prensa, radio, todos los órganos opinión, no existe opinión pública, la hace

57 Ibídem, p. 54.

58 Ismael SAZ, «Mucho más que crisis políticas: el agotamiento de dos proyectos enfrentados", Ayer, 68, 2007, pp. 137-I63.

Cercles. Revista d'História Cultural, 24 (2021), 153-183. ISSN: 1139-0158. e-ISSN: 1699-7468. DOI: 10.1344/cercles2021.24.1005. 
el Gobierno».59 I en diverses ocasions es feu ressò davant Pius XII de la poca idoneitat d'alguns candidats que sonaven per proveir algunes seus vacants, "ciertos eclesiásticos completamente desacreditados e indeseables». ${ }^{60}$ Mentre que, d'altra banda, temia possibles depuracions entre el clergat català, similars a l'efectuada als organismes públics. ${ }^{61} \mathrm{El}$ cardenal no es cansava de denunciar les complicitats entre religió i política:

[...] prestan a la Iglesia el flaco Servicio de hacer que ante los ojos de la gente simple, que es la gran mayoría, aparezcan mezclados y confundidos los intereses altísimos y permanentes de la Religión con los siempre más deleznables y transitorios de un régimen político, en último término con evidente detrimento de la Iglesia que se ve más o menos envuelta en el fracaso que tarde o temprano acabe por corroir a las Instituciones políticas y temporales. ${ }^{62}$

Unes paraules que mostren la clarividència del cardenal envers les conseqüències funestes que acabaren derivant-se de la doctrina nacionalcatòlica sobre la pràctica de la religió. Encara més, posava en dubte el sentiment catòlic de bona part del falangisme, així com l'autenticitat del catolicisme que propugnava el règim, tal com expressava, per exemple, en un dels seus informes:

[...] lo más sensible es el empeño tan marcado que de un tiempo acá ponen el Gobierno y la misma Falange en proclamarse católicos, con lo cual ante las masas populares aparece la Iglesia vinculada al Gobierno y Falange y harán de la misma objeto de aversión y antipatía que les merece el Gobierno por su ineptitud en la buena marcha de la cosa

59 AMCAM, Memòries..., p. I8.

60 Ibídem, p. 99-5.

6I Ibídem, p. 88.

62 Ibídem, p. 99-9.

Cercles. Revista d'Història Cultural, 24 (2021), 153-183.

ISSN: 1139-0158. e-ISSN: 1699-7468. DOI: 10.1344/cercles2021.24.1005. 
pública. Les secundan algunos eclesiásticos, que con ello esperan medrar, religiosos (Jesuitas) y aún algunos Obispos, bien que no haya faltado alguna voz autorizada de alarma denunciando el peligro de seguir silenciando ciertos errores que van irrumpiendo por España. ${ }^{63}$

No sabrem mai si, amb aquests errors silenciats, es referia a la repressió desfermada pel règim, sobre la qual l'Església es mostrà majoritàriament cega i callada. En tot cas, el cardenal no deixava d'alertar el papa d'algunes decisions de Franco en matèria religiosa que estimava desencertades. El govern espanyol havia començat a fer importants concessions a l'Església, alhora d'haver protagonitzat algunes actuacions que extralimitaven les competències de l'Estat en matèria eclesiàstica. En concret, es donava la circumstància que els tres cardenals espanyols d'aleshores estaven desenganyats amb el dictador per diversos incidents i intromissions: Vidal, exiliat sense possibilitat de retorn; Gomà, malalt, que morí l'agost del I940, desconcertat per la censura governamental a la seva última pastoral; i Segura, tan particular com sempre, al cap i a la fi un monàrquic convençut que Franco intentà expulsar per les seves sortides de to continuades $i$ crítiques a determinats aspectes del règim. Allò en què coincidien els tres prelats era el rebuig del totalitarisme del règim, verificat pel predomini de la Falange i per les simpaties amb el nazisme alemany, que tant alarmaven el Vaticà. Tot i això, la major part dels bisbes acceptaren el feixisme del règim sense gaire escrúpols. ${ }^{64}$

Vidal advertí al Sant Pare la inoportunitat d'algunes demandes del govern espanyol durant les negociacions diplomàtiques que acabaren en l'assoliment d'un conveni bilateral en matèria de presentació de bisbes el juny del I94I. En una carta del 9 de febrer, el carde-

63 Ibídem, p. 99-4.

64 Alfonso Botтı, «Iglesia y totalitarismo: el caso español (I936-I939)», Historia y Politica, 28, 20I2, pp. 3I-55. 
nal, que estava assabentat de les negociacions, recomanava al Vaticà que, abans d'arribar a un acord, calia tenir la seguretat que existia un Estat constituït amb garanties suficients. Al mateix temps, alertava de les intencions del nunci Cicognani, que, més aviat, «[...] parece empeñado en atraer a la Santa Sede a los puntos de vista del Gobierno que no en convencer a éste de la razonable actitud de la S. Sede». ${ }^{65}$ En efecte, Cicognani fou, juntament amb el pare Ledokowsky, prepòsit general de la Companyia de Jesús, un dels principals valedors del règim de Franco davant del Vaticà. ${ }^{66}$

\section{El paper del Vaticà}

La premsa espanyola només tingué permesa la publicació d'una discreta informació sobre el traspàs de Vidal i Barraquer, extreta d'un breu comunicat de l'agència EFE. Viladrich no podia estar menys molest per l'actitud de Franco, a qui acusà de cínic arran de la notícia de la mort del cardenal. En efecte, el dictador envià una carta als bisbes espanyols en què els demanava que es fessin precs i sufragis pel cardenal a totes les esglésies. També a Roma, a l'església espanyola, on se celebraren els funerals el 25 de setembre de I943, amb l'assistència del cardenal Maglione. Viladrich considerava aquestes celebracions litúrgiques pròpiament un escarni: "Ens semblava més noble el silenci davant l'adversari caigut». ${ }^{67}$ I pensava, a més, que els suposats honors que se li volien retre al cardenal contravenien el desig expressat en les seves notes testamentàries. Aquestes opinions les compartí Viladrich en una lletra adreçada a Pius XII el 5 de novembre: «no pasa de una pura farsa para disimular ante el mundo diplomático y

65 AMCAM, Memòries..., p. 68 quindec.

66 MARQuina, op. cit., I983, p. 289.

67 AMCAM, Memòries..., p. I22.

Cercles. Revista d'Història Cultural, 24 (2021), 153-183.

ISSN: 1139-0158. e-ISSN: 1699-7468. DOI: 10.1344/cercles2021.24.1005. 
eclesiástico de la Ciudad Eterna un estado de hecho vergonzoso para un Gobierno que se quiere preciar de católico». ${ }^{68}$ Per a Viladrich, la desaparició del cardenal arquebisbe tancava el cas de vacança de la seu de Tarragona, sense que el Vaticà hagués aconseguit imposar-se sobre una qüestió que violava el dret canònic. Segons el canonge secretari, fou el novembre del 1939, durant una audiència papal, que Vidal i Barraquer prengué consciència de la poca decisió per imposar al govern el seu retorn: «La Santa Seu no s'avenia a guillotinar el Cardenal per fer content el Govern. Però tampoc no accedia a la petició insistent del Cardenal de donar-li el permís per anar a Tarragona. Entre tant, qui no pot segar, espigola. El Govern, de fet, s'havia tret del davant el Cardenal». ${ }^{69}$ Aquesta fou l'estratègia de Franco: mirar d'allargar una improbable solució a l'afer fins que arribés l'hora de la desaparició del cardenal, ja aleshores amb una salut prou delicada. Aquest, desesperat per l'aparent inacció (o, almenys, la ineficàcia de les accions) del Vaticà, no es cansava de recordar al Papa la seva trajectòria d'exemplar obediència i acatament a la jerarquia eclesiàstica. Així doncs, Viladrich no pot deixar de retreure a la Santa Seu el seu paper massa indulgent amb Franco:

Volem consignar, ara que ve a tomb, que el Cardenal amb els quatre anys i mig de pledejar prop del Vaticà el seu dret de retornar a Tarragona oposant-se a la pretensió arbitrària del Govern, no pot ensenyar ni un sol document de la Santa Seu dient-li que la raó està de la seva banda i que justifiqui que la Santa Seu ha defensat sempre els drets del Cardenal prop del Govern. El Cardenal [...] no ha rebut del Vaticà més que paraules i més paraules [La Santa Seu] devia haver fet sentir més a Franco com havia estat incorrectíssima la seva actitud perseguidora contra el Cardenal Metropolità de Tarragona, degà dels Cardenals espanyols. ${ }^{70}$

68 Ibídem, p. 138.

69 Ibídem, p. 66.

70 Ibídem, p. IO2.

Cercles. Revista d'História Cultural, 24 (2021), 153-183. ISSN: 1139-0158. e-ISSN: 1699-7468. DOI: 10.1344/cercles2021.24.1005. 
L'esclat de la guerra havia situat Vidal i Barraquer en una posició inicial de preferència pel bàndol sollevat, especialment una vegada verificada la persecució religiosa a la rereguarda, que colpí molts catòlics espaordits per aquell inusitat grau de violència. Després de la guerra, en canvi, cal admetre-li un profund desengany havent comprovat els mètodes $\mathrm{i}$ les intencions del nou règim instaurat, massa embrancat en les represàlies i les intromissions en afers religiosos. El cardenal desaprovà el règim de Franco i hauria preferit, sens dubte, la restauració de la monarquia. Fins a la guerra, Vidal representava una alternativa, una altra Església. ${ }^{71}$ Així ho veia Cardó, també. Tanmateix, no fou un dissident ni potser tampoc un «catòlic contra corrent». Per a López Villaverde, el cardenal català fou un personatge que restà en terra de ningú. ${ }^{72}$ Un pastor de l'Església que, encara que hagués retornat, no s'hauria emmotllat a la nova realitat. Tal com ha apuntat Martín de Santa Olalla, l'Església fou capaç de sacrificar-lo per tal de pactar amb el règim. ${ }^{73}$

\section{Conclusió}

La crònica del canonge Joan Viladrich, secretari particular del cardenal Vidal i Barraquer, mostra en detall la llarga lluita del prelat tarragoní davant l'alta jerarquia vaticana, gairebé sempre tractant directament amb el pontífex romà, per tal de reparar una qüestió que, des del primer moment, tant Vidal com el Vaticà acordaren que era injusta i contrària al dret canònic: la seva proscripció per part del govern de Franco. Viladrich exposa les freqüents intromissions dels vencedors de la guerra en els afers eclesiàstics nacionals, però també el

7I Massot, op. cit., maig de 1978.

72 Ángel Luis López VILLAVERDE, «El factor católico y la cultura política antifascista», Revista de Historia Actual, Iо, 2012, pp. 77-86.

73 Martín de Santa Olalla, op. cit., 2003, p. 244. 
paper del cardenal Gomà, que el canonge solsoní acusa d'haver intrigat especialment contra Vidal davant de Franco mateix. Precisament, aquestes orquestracions de la cúria espanyola són valorades amb especial sentiment pel secretari del cardenal:

La malícia de la violència, la traïció dels amics i la feblesa o temor d'espatllar la carrera dels altres, unides en vergonyós maridatge, infantaren un producte híbrid [corregit per: un monstre] digne dels progenitors: el flagrant atropell contra la jurisdicció eclesiàstica de Tarragona $[. ..] .^{74}$

Vidal i Barraquer no simpatitzava, evidentment, amb la República, però, d'altra banda, no sentia una adhesió gens entusiasta pels militars rebels, ni, encara menys, oberta. El cardenal havia passat per experiències ben desagradables en les seves relacions obligades amb els militars del Directori de Primo de Rivera, de manera que coneixia prou bé què se'n podia esperar. ${ }^{75}$ Antics militars primoriveristes, gent de Renovación Española i els integristes catòlics foren els principals oponents a la línia moderada dins l'Església espanyola que representava Vidal i Barraquer, d'acord — no ho oblidem — amb la postura de Pius XI. Desaparegut aquest darrer el febrer del 1939, cal preguntar-se si Vidal i Barraquer fou també un personatge massa incòmode per al Vaticà. L'obertura recent de l'accés als fons documentals del pontificat de Pius XII haurà de permetre indagar en aquest aspecte del cardenal arquebisbe de Tarragona i, per extensió, de la història de l'Església del nostre país.

74 AMCAM, Memòries..., p. 64.

75 Muntanyola, op. cit., 2017. els autors, citats a la referència que apareix a l'inici del document. 